\title{
Wells syndrome associated with gastrointestinal lymphoma
}

\author{
Zaouri $\mathrm{H}^{*}$, El Makrini N, Berbich L, Senouci K, and Hassam B \\ Department of Dermatology, Venereology, CHU Ibn Sina, Rabat-Morocco
}

\begin{abstract}
Wells syndrome is an eosinophilic dermatitis, especially described in association with infections or after insect bites, rarely during a hematologic disease. Herein, we report a case of a 52 years old female, who had a six months' history of a polymorphic eruption, made of bullous lesions and inflammatory skin closet on the trunk and lower limbs, relapsing remitting, in whom they had just diagnosed a lymphoma B MALT-type of the rectosigmoid. A skin biopsy performed at two sites showed a dermal infiltrate rich in eosinophils compatible with Wells syndrome. Biology did not reveal hyper eosinophilia. A chemotherapy "R-CHOP" was indicated for her hematological malignancy. The evolution was marked by the disappearance of skin lesions after the 3rd course of chemotherapy. Through this case report, we highlight the importance of knowing this rare entity, which can reveal or accompany a hematologic malignancy.
\end{abstract}

\section{Introduction}

Wells syndrome is a rare condition of unknown cause. It is also called "eosinophilic cellulitis". Herein, we report a new case of Wells syndrome associated with gastrointestinal lymphoma.

\section{Clinical case}

A 52 years old female, who presented with six months history of a polymorphic eruption, made of bullous lesions and inflammatory skin closet of the trunk and lower limbs (Figure 1,2), in whom they had just diagnosed a lymphoma B MALT-type of the rectosigmoid. A skin biopsy performed at two sites showed a dermal infiltrate rich in eosinophils compatible with Wells syndrome (Figure3). Biology did not reveal hyper eosinophilia. A chemotherapy "R-CHOP" was indicated for her hematological malignancy. The evolution was marked by the disappearance of skin lesions after the 3rd course of chemotherapy (Figure 4).

\section{Comments}

First described by George C. Wells as "recurrent granulomatous dermatitis with eosinophilia" in 1971, and renamed as "eosinophilic cellulitis" and Wells' syndrome in 1979 [1]. The exact pathogenesis is still unknown; however, local hypersensitivity to various triggers, such as arthropod bites and stings, viral and parasitic infections, drugs reactions and hematologic and non-haematological malignancies have been proposed [2]. Clinical manifestations include annular

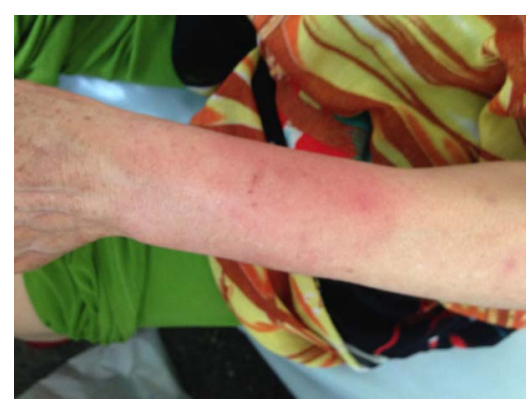

Figure 1. Inflammatory closet of the left forearm. reddish plaques with oedema, urticaria or even blisters, vesiculae and hemorrhagic bullae, but also papules, nodules with a recurrent burning or itching sensation, and sometimes with fever [2-5]. Eosinophils play an important role in the typical histology of Wells syndrome, showing a dermal infiltrate of eosinophils with an admixture of lymphocytes and histiocytes. Flame figures, collagen fibres with eosinophil granules, are a hallmark of Wells syndrome, but can also be associated with other diseases, such as parasitic, viral, fungal or bacterial infections, arthropod bites, mastocytoma, drug reactions, eczema, various malignancies, urticaria, hypereosinophilic syndrome or Churg-Strauss disease [6].

There have been a few reported cases of Wells syndrome associated with non-haematological malignancies, such as one case each of : squamous cell carcinoma of the bronchus, adenocarcinoma of the lung, adenocarcinoma of the colon, and nasopharyngeal carcinoma, where skin lesions cleared after successful treatment of the underlying malignancy using either chemotherapy or surgical resection [7-10].

In summary, our observation emphasizes the importance of knowing this rare entity, which can reveal or accompany a hematologic malignancy.

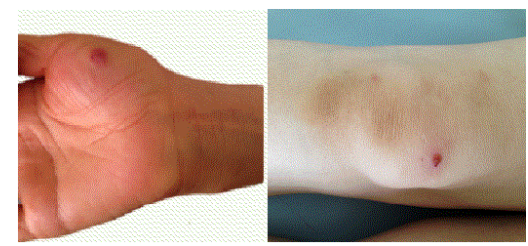

Figure 2. Damage bullous hemorrhagic content had the palmar surface of the right hand against the right knee.

Correspondence to: Zaouri H, Department of dermatology, Ibn Sina Hospital University Rabat, Morocco, Tel: 00212661223823; E-mail: hasnaazaouri@yahoo.fr

Keywords: eosinophilic cellulitis; hematologic disease; wells syndrome; gastrointestinal lymphoma; chemotherapy

Received: September 15, 2016; Accepted: October 07, 2016; Published: October 10,2016 


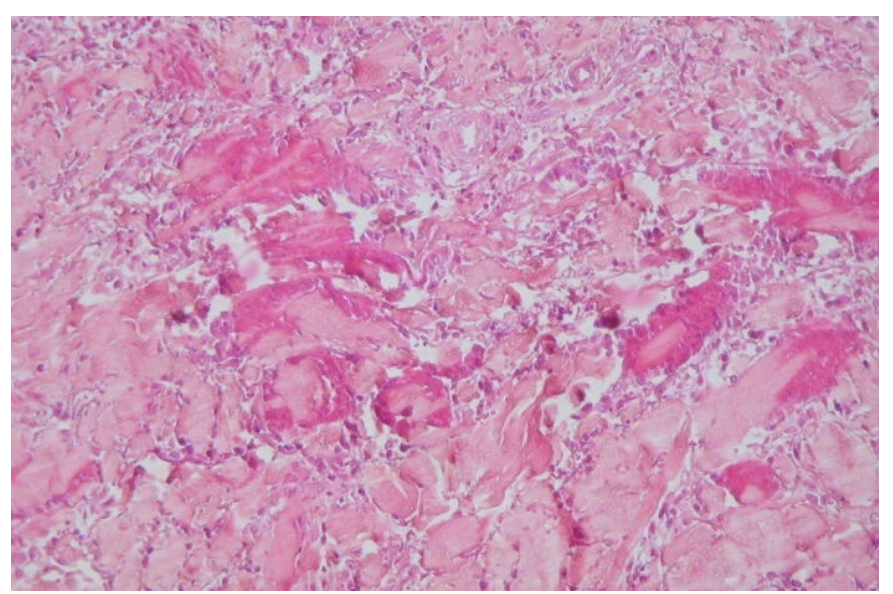

Figure 3. Dermal infiltrate rich in eosinophils degranulated contact fragmented collagen fibers and basophils, in favor of Wells syndrome.
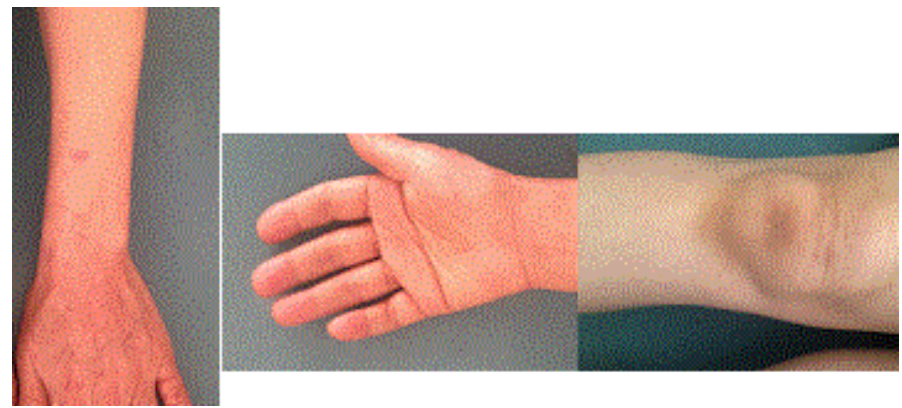

Figure 4. The disappearance of lesions after the third cycle of chemotherapy.

\section{Conflict of interests}

None.

\section{References}

1. Burket JM (1981) Wells' syndrome: recurrent granulomatous dermatitis with eosinophilia. [Crossref]

2. Holme SA, McHenry P (2001) Nodular presentation of eosinophilic cellulitis (Wells syndrome). Clin Exp Dermatol 26: 677-679. [Crossref]

3. Mechow N, Cosgarea I, Ogwang E (2013) Gigantic Erythematous Plaques with Violaceous Oedematous Borders: A Quiz. Acta Derm Venereol 93: 607-609.

4. Soua Y, Akkari H, Sriha B, Belhadjali H, Zili J (2014) Bullous lesions on the wrists Ann Dermatol Venereol 141: 717-719. [Crossref]

5. Schuttelaar ML, Jonkman MF (2003) Bullous eosinophilic cellulitis (Wells' syndrome) Sassociated with Churg-Strauss syndrome. J Eur Acad Dermatol Venereol 17: 91-93. [Crossref]

6. Consigny S, Courville P, Young P, Richard C, Gauthier V, et al. (2001) Histological and clinical forms of the eosinophilic cellulitis. Ann Dermatol Venereol 128: 213-216. [Crossref]

7. Farrar CW, Guerin DM, Wilson NJ (2001) Eosinophilic cellulitis associated with squamous cell carcinoma of the bronchus. Br J Dermatol 145: 678-679. [Crossref]

8. Skellett A, McCann B, Levell N (2009) Eosinophilic cellulitis caused by adenocarcinoma of the lung. Int J Dermatol 48: 1402-1403. [Crossref]

9. Hirsch K, Ludwig RJ, Wolter M, Zollner TM, Hardt K, et al. (2005) Eosinophilic cellulitis (Wells' syndrome) associated with colon carcinoma. J Dtsch Dermatol Ges 3: 530-531. [Crossref]

10. Murray D, Eady RA (1981) Migratory erythema and eosinophilic cellulitis associated with nasopharyngeal carcinoma. J R Soc Med 74: 845-847. [Crossref]

Copyright: @2016 Zaouri H. This is an open-access article distributed under the terms of the Creative Commons Attribution License, which permits unrestricted use, distribution, and reproduction in any medium, provided the original author and source are credited. 